\title{
Etching of $\mathrm{YBa}_{2} \mathrm{Cu}_{3} \mathrm{O}_{\mathrm{y}}$ surface by scanning tunneling microscope
}

\author{
S. Chen ${ }^{a}$, L. M. Wang ${ }^{a}$, H. C. Yang ${ }^{a}$, and H. E. Horng ${ }^{b}$ \\ aDepartment of Physics, National Taiwan University, Taipei, Taiwan, R. O. C. ${ }^{*}$ \\ bepartment of Physics, National Taiwan Normal University, Taipei, Taiwan, R. O. C.
}

We report the controlled and systematic modification with scanning tunneling microscope (STM) of the surface in bilayer $\mathrm{YBa}_{2} \mathrm{Cu}_{3} \mathrm{O}_{\mathrm{y}} / \mathrm{PrBa}_{2} \mathrm{Cu}_{3} \mathrm{O}_{\mathrm{y}}(120 / 960)$ films. The number in parenthesis refers to the thickness of each layer in units of Angstrom. The bias voltage of the tip was kept negative and was varied from -600 to $-1200 \mathrm{mV}$. The tip was operated in a constant tunneling mode with $0.3-0.6 \mathrm{nA}$ of tunneling current and the scanning rate was $1 \mathrm{~Hz}$. Etching of the YBCO/PBCO (120/960) begins with a nucleation of holes and can be achieved by successive scan ning a fixed area.

The scanning tunneling microscope (STM) has been successfully used to characterize the surface morphology of high- $\mathrm{T}_{\mathrm{c}}$ oxides, including single crystals [1,2] and thin films [3]. Atomic resolution has been achieved on single crystal and atomic flat area separated by steps of one or more unit cells in heights has been identified as the characteristic surface topography in $\mathrm{YBa}_{2} \mathrm{Cu}_{3} \mathrm{O}_{\mathrm{y}}(\mathrm{YBCO})$ films. In addition to the surface characterization, the STM has been proved to be a very useful tool to induce controlled modification of material surfaces, such as surface etching of $\mathrm{YBa}_{2} \mathrm{Cu}_{3} \mathrm{O}_{\mathrm{y}}$ (YBCO) single crystal [4,5], and mechanical milling of flat surface in $\mathrm{YBCO}$ and $\mathrm{Bi}_{2} \mathrm{SrCa}_{2} \mathrm{Cu}_{2} \mathrm{O}_{\mathrm{y}}$ films [6,7]. In this work we report the surface morphology and systematic modification with the STM of the bilayer $\mathrm{YBa}_{2} \mathrm{Cu}_{3} \mathrm{O}_{\mathrm{y}} / \mathrm{PrBa}_{2} \mathrm{Cu}_{3} \mathrm{O}_{\mathrm{y}}$ (YBCO/PBCO) films.

The surface characterization and modifications were performed by the STM system (Park Scientific Instruments), operating in air at room temperature. All images were recorded using chemical etched tungsten tip. The tip was operated in a constant tunneling current mode and the scanning rate was 1 Hz. The bias voltage on the sample is kept negative and varied between -600 and $-1200 \mathrm{mV}$. The bilayer YBCO/PBCO (120/960) films were prepared by an off axis if magnetron sputtering system from stoichiometric $\mathrm{YBa}_{2} \mathrm{Cu}_{3} \mathrm{O}_{\mathrm{y}}$ and $\mathrm{PrBa}_{2} \mathrm{Cu}_{3} \mathrm{O}_{\mathrm{y}}$ (PBCO) targets. The number in parenthesis refers to the thickness of each layer. PBCO layer of $960 \mathrm{~A}$ thick was chosen as a buffer layer so thin YBCO films (10 units of YBCO cells) can be grown on $\mathrm{SrTiO}_{3}(001)$ with $\mathrm{T}_{\mathrm{c} \text {, zero }}$ at $78 \mathrm{~K}$.

Figure 1 shows the evolution of the surface topography with increasing scanning time for a

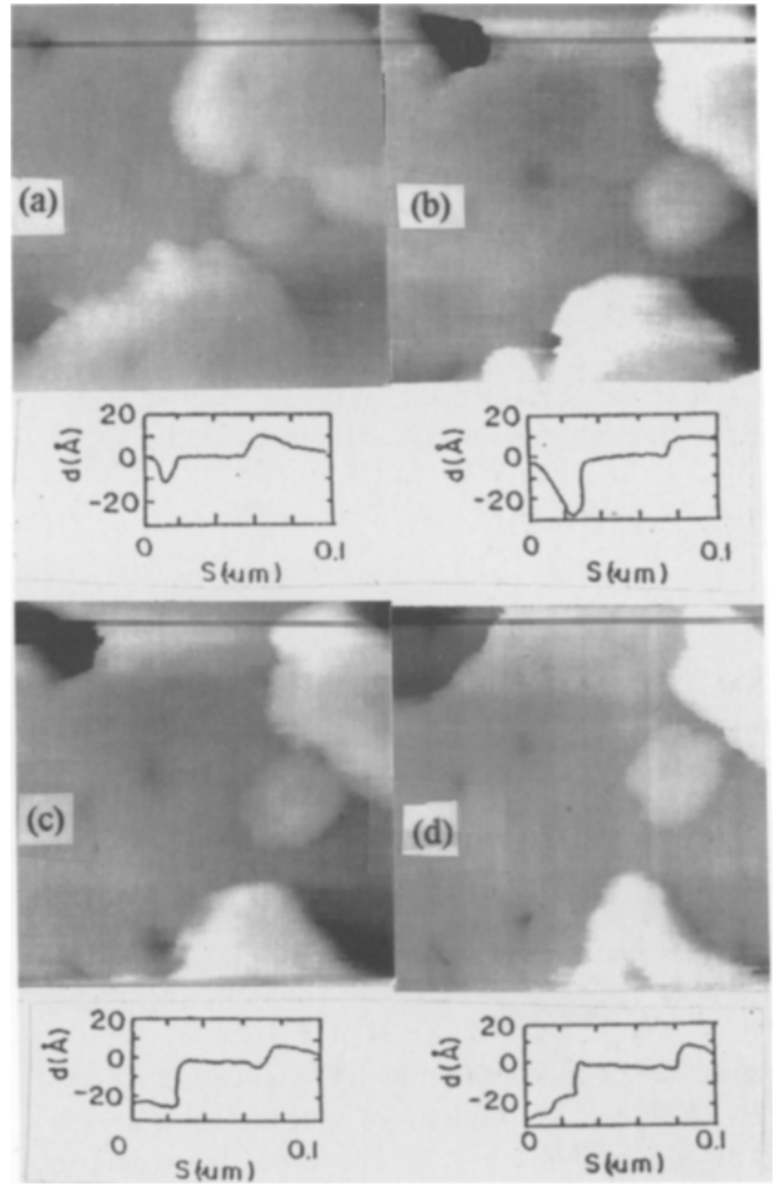

Figure 1. Successive scanning for $\mathrm{YBCO} / \mathrm{PBCO}$ films (12 $\mathrm{nm}$ thick) using the STM over the same area: (a) $n=6$, (b) $n=11$, (c) $n=12$, and (d) $n=$ 13. The time in each scan is $256 \mathrm{sec}$. A cross section is given for all images showing the variation of the height $\mathrm{d}$ as a function of the distance. 
fixed area for sample a. The tip bias voltage $(-0.745$ $\mathrm{V})$ and the tunneling current $(0.42 \mathrm{nA})$ were kept constant during the whole scanning procedures. The scanning area is $100 \times 100 \mathrm{~nm}^{2}$. For each image, a cross section is also shown at approximately at the same $y$ direction to provide a quantitative information of the etching profile. It is clear that from the various imaging that the film surface is modified by successive scans. The modification of the surface is even more obvious if one focus on the evolution of the hole at the left-upper corner or the layer at the center of the image. The depth of the hole is about $12 \mathrm{~A}$ and the step height of the YBCO layer is also about one unit YBCO cell. Layer structure in YBCO/PBCO (120/960) films is observed for $12 \mathrm{~nm}$ thick YBCO films .

Figure 2 shows the evolution of the surface mor-

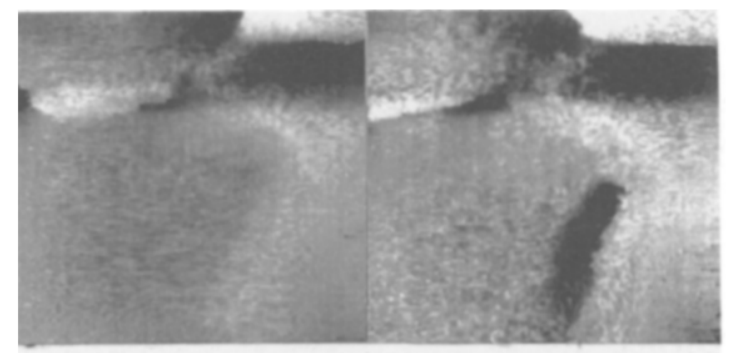

(a)

(b)

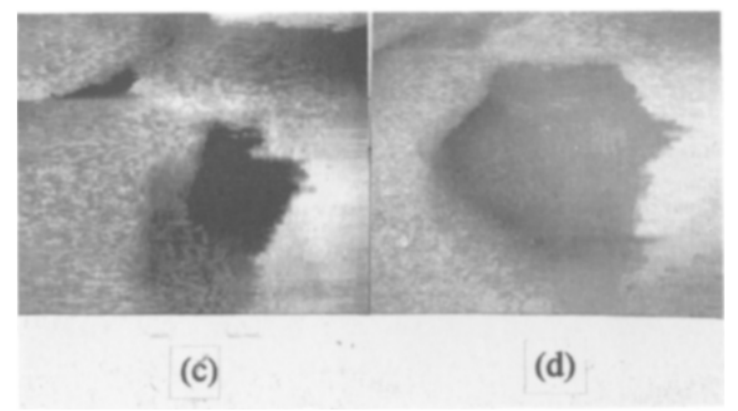

Figure 2. Evolution of the STM imaging of the YBCO films ( $12 \mathrm{~nm}$ thick) for : (a) $\mathrm{n}=2$, (b) $\mathrm{n}=4$, (c) $n=6$, and (d) $n=8$. The time between two successive scans is $256 \mathrm{sec}$. The scanning area is $100 \times 100 \mathrm{~nm}^{2}$ phology with increasing scanning time for a fixed area at a different position of sample a. The tip bias voltage is $-0.832 \mathrm{~V}$ and the tunneling current is $0.53 \mathrm{nA}$. A hole is developed and clearly modified by the successive scanning. It is observed that the etching began with the nucleation of holes and upon repeated scanning, the holes grow until an layer of the material is removed.

The use of the STM as a tool to reveal microstructural features of the surface topology in thin films can give insight the growth mechanisms. As the films grows the islands grows and coalescence into a more continuous layer structures [3]. The present observation of the layer structures in the YBCO/PBCO $(120 / 960)$ films perhaps suggests that the buffer PBCO films help the coalease of the islands of into the YBCO layer

In summary we observe the surface morphology and etching of YBCO/PBCO (120/960) films using the STM. Layer structures are observed in the surface morphology in $12 \mathrm{~nm}$ thick YBCO films buffered with the PBCO layer. Etching of the surface of the YBCO/PBCO films can be achieved by successive scanning of a fixed area.

\section{References:}

1. L. H. Edward, J.T. Markert and A.L. de Lozanne, Phys. Rev. Lett. 69, 2967 (1992).

2. L.E.C. Van de Leempart, P.J.M. van Bentum, L.W.M. Schreurs, and H. Van Kempen, Physica, C152, 99 (1988)

3. H. Haefke, H. P. Lang, G. Leemann, and H.-J. Guntherodt, Appl. Phys. Lett. 60, 3054 (1992).

4. A. V. Narlikar, P.K. Dutta, S.B. Samanta, O.N. Srivastava, P. Ramasamy, S.C. Sabarwai, M.K. Gupta and B.D. Padalia, Appl. Phys. Lett. 60 , 1896 (1992).

5. M. A. Harmer, Curtis R. Fincher and B.A. Parkinson, J. Appl. Phys. 70, 2760 (1991).

6. I. Heyvaert, E. Osquiguil, C. Van Haesendonck and Y. Bruynseraede, Appl. Phys. Lett. 61, 111 (1992).

7. K. Terashima, M. Kondoh, Y. Takamura, H. Hisashi, and Komaki, Appl. Phys. Lett. 59, 644 (1991).

\footnotetext{
${ }^{*}$ This work is supported by National Science Council of R.O.C. under contract No. NSC 81-0212-M002-553.
} 